\title{
The Identity Game: Michel Foucault's Discourse-Mediated Identity as an Effective Tool for Achieving a Narrative-Based Ethic
}

\author{
Steve Urbanski*
}

Perley Isaac Reed School of Journalism, West Virginia University, Morgantown, WV, USA

\begin{abstract}
This article examines in hermeneutic fashion the philosophy of Michel Foucault and isolates an identity matrix that can assist humans in navigating the often numerous and conflicting narratives facing us in the $21^{\text {st }}$ century and empower us to move toward a more narrative-based ethic that is beneficial to multiple stakeholders. Of particular interest is Foucault's assertion that our identities are not fixed in a traditional sense but mediated by the many rich, dialogical discourses we encounter each day. This identity scheme is suggested in much of Foucault's philosophy, particularly in Discipline and Punish and The History of Sexuality, and its application to ethics has never been more important. As highly developed countries, particularly the United States, become more egocentric, ethical decision-making too often is defined via an emotivistic framework. Foucault's thoughts on identity can enlighten us to the power each person has in determining and taking ethical action that can positively inform what this article terms a narrative-based ethic. This portion of the article is informed by philosopher Walter R. Fisher, who sees humans as "storytellers" who view the world based on an awareness of what Fisher terms narrative probability - or what constitutes a coherent story - and their constant habit of testing that story's narrative fidelity, whether the experience rings true with other stories they know to be true in their lives.
\end{abstract}

Keywords: Culture, ethics, genealogy, identity, narrative.

\section{INTRODUCTION AND THESIS STATEMENT}

In his third essay of Genealogy of Morals, Friedrich Nietzsche [1] posits the individual in his definition of the ascetic ideal by proclaiming, "Let the world perish, but let there be philosophy, the philosopher, me!" (p. 108). Gilles Deleuze [2] complicates this concept somewhat when he finds a space for ethics in his discussion of active and reactive forces - both of which play major roles the ascetic ideal - when he writes, "Eternal return, as a physical doctrine, affirms the being of becoming. But, as selective ontology, it affirms this being of becoming as the 'self-affirming' of the becoming-active" (p. 72).

Within these two passages, Nietzsche and Deleuze illustrate an interesting dialectic: Within Nietzsche's work as a genealogist, there are forces of identity and ethics playing off of and competing with one another. The ethical dimension of an "eternal return" affirms the "being of becoming," about which Deleuze writes.

Although Nietzsche's genealogies undermine the narratives and social practices that guide us as ethical beings, his genealogies were, in essence, works of deconstruction long before Jacques Derrida made the practice famous (and infamous, depending on one's philosophical orientation) more than 70 years later. By questioning the value of the values themselves, a Nietzschean genealogy, is a purification of sorts, which calls into question the very values humans hold

*Address correspondence to this author at the Perley Isaac Reed School of Journalism, West Virginia University, Morgantown, WV, USA;

Tel: 304-293-6797; Fax: 304-293-3072;

E-mail: steve.urbanski@mail.wvu.edu sacred. By toppling these philosophical barriers, or at least lessening their effectiveness, Nietzsche hopes to open a space for a new, purer form of thought.

The process of deconstruction can have the same result; however, the operative word is can. Many scholars agree that deconstruction has much the same effect as a Nietzschean genealogy. Its aim is to destabilize a subject by constantly questioning the social practices (such as values and even language) and thus open that subject to a richer understanding. However, not all forms of deconstruction can be looked upon with such disdain. Several works by Derrida, among them "Structure, Sign, and Play in the Discourse of the Human Sciences" [3] and "The Principle of Reason: The University in the Eyes of Its Pupils" [4], are not intended to destroy discourses but rather disrupt them, open them to new discussion, and ultimately to more comprehensive meaning.

A example is Gayatri Spivak's [5] essay "Feminism and Critical Theory" in which she outwardly accepts the patriarchy but destabilizes it by effectively questioning key aspects of Marxism and Freudianism, thus opening the patriarchy and allowing a space for a feminist discussion. Spivak takes Marxian view of production, for example, and changes it to REproduction, while Freud's pleasure principle is destabilized by Spivak's suggestion that childbirth is anything but a pleasurable experience. Spivak does not want to destroy the texts of Marx and Freud. She merely proposes a different way of reading them, one that includes a feminist voice.

A logical successor in this philosophical and ethical chain is Michel Foucault. His genealogical approach aligns him with both Nietzsche and Derrida, yet Foucault is a difficult philosopher to classify. At times he is a structuralist, at 
other times a post-structuralist or a post-modernist. Two of his most notable works Discipline and Punish: The Birth of the Prison [6] and The History of Sexuality: An Introduction [7] are genealogies and both, in true Nietzschean fashion, bring into question the values and social practices that underpin our ethical makeup.

However, within Foucault's systematic approach to questioning ethics and values is a distinct method that can be beneficial in a post-modern time of competing narratives. This method begins with his belief that identity is not fixed but rather a discourse mediated by our interactions with others [8].

This project will investigate how Foucault's notion of an unfixed, discourse-mediated identity can assist us in overcoming emotivism and egoism and propel us toward a more narrative-based ethic. This relationship, in all likelihood, may have been unknown even to Foucault; however, the usages are significant if we are to achieve an ethic that is communitarian-like, not one that is emotivist in nature. The term narrative-based ethic deserves some expansion. For the purposes of this essay, it is a communitarian-type of ethic that is informed by our lived experiences that recognizes the collective nature of the world in which we live. Walter Fisher [9] terms humans as "storytellers" who possess an inherent awareness of "narrative probability," what constitutes a good story, and "narrative fidelity," (p. 5) whether those stories ring true with the other stories within their lives. Fisher's narrative paradigm provides a contemporary (and logical) lens through which to view Foucault's work. Fisher has been adamant about the paradigm not being a celebration of narration as much as it is a celebration of human beings by "... reaffirming their nature as storytellers" [10] (p. 56). Foucault was never shy about undermining biological, psychological, or social truths, usually purporting that they are merely outcomes of contingent historical forces. These contingent historical forces, at least for the purposes of this essay, are the bridge between Fisher and Foucault. In Fisher's philosophy, the many stories that bind us together and ultimately construct our reality are fueled by history. This history is the roots of his narrative fidelity. For Foucault, history becomes more of a frame or a boxing ring where preconceived truths can be isolated and taken apart in an effort to expose or create new knowledge.

\section{A METHODOLOGY OF HERMENEUTICS}

This project will involve comparing and contrasting in hermeneutic fashion a number of Foucault's works in an attempt to illustrate his realm of the unfixed identity. Other texts, such as the above-mentioned Discipline and Punish and The History of Sexuality, will elucidate how Foucault frames both the individual and ethics. Within these relations is a method by which we can realize the unfixed nature of our identities and move beyond them by realizing the vital role "the other" plays in our interpersonal actions.

This realization of and movement beyond identity is a radical concept but one that may be a natural phenomenon in narrative-based ethical structures. A narrative includes an appreciation of the other and the natural connection everyone has to history, language, the present, and the future. Our place in this equation can be active or passive. When it is passive, we are vulnerable to Nietzschean-like ressentiment, which can be paralyzing and destructive. However, when we are active, new communicative possibilities arise and assure a connection to an ethic that includes a multiplicity of voices and social practices.

Individual characters are quite distinctive in many of Foucault's texts, yet how he defines the concept of identity opens a space for communicative and ethical transformation. It will be necessary to first examine Foucault's concept of identity and then posit that concept within Discipline and Punish and The History of Sexuality to illustrate the transformative power of an unfixed identity.

Finally, through an examination of Foucault's "Technologies of the Self" [11], a better recognition of the link between identity (fixed or otherwise) and ethics will emerge and the greater challenge to look beyond identity, ego, and emotivism when facing ethical quandaries. As Foucault neared the end of his life (because he had AIDS in the 1980s, he knew he would die), his outlook on life, knowledge, and the other changed radically. An offshoot of this change was a preoccupation with subjectivity and practices of the self. At times Foucault's later writings are puzzling and in direct conflict with his earlier material. He retreated from his more politically engaging texts (i.e., Discipline and Punish and The History of Sexuality) and undertook a project that can best be described by Sawicki [12] as self-refusal — "to become someone else you were not at the beginning" (p. 288). For this abrupt change to have significance within a discussion of ethics, ego, identity, and emotivism, it is significant to first look at earlier Foucauldian concepts of identity to illustrate how they changed at different points of his life.

\section{A Question of Identity: "What is an Author?"}

Foucault's 1969 lecture (which later became an essay) perhaps best illustrates his notion of human identity being essentially a discourse that is mediated by our interactions with others. In "What is an Author?" [13] Foucault re-casts the idea of the author, denying its status as a unified consciousness capable of explaining the final meaning of the text. Instead, Foucault describes the author as a set of functions or leverage points that enable the production of a final meaning. From the start of his essay, Foucault refers to the author/work relationship as "... a solid and fundamental unit" [13] but quickly adds:

I want to deal solely with the relationship between text and author and with the manner in which the text points to this figure that, at least in appearance, is outside it and antecedes it (p. 205).

Immediately Foucault is suggesting that there is an unavoidable link between the two, the moment the work is conceived and during the actual writing process. However, his reference to the author as "this figure" also illustrates his feelings of detachment for the author as an actual identity. The author is "outside" the work being created and he/she also antecedes it or exists prior to the creation of the work. Once the piece is written, a distinct break occurs between author and work.

"Writing unfolds like a game," Foucault [13] writes, "that $[j e u]$ that invariably goes beyond its own rules and transgresses its limits" (p. 206). Eventually a point arises when the text assumes an existence of its own and is linked 
to the author in only an associative manner. The work, in fact, is able to give rise to subsequent independent discourses, which continue in different forms even after the author's death. While the author is alive, Foucault [13] notes that he "... must assume the role of the dead man in the game of writing" (p. 207).

This odd role of the dead man is Foucault's way of dealing with the cultural manner in which we have "... metamorphosed this idea of narrative, or writing, as something designed to ward off death" (p. 206). The text is essentially immortal but in the case of (among others) Flaubert, Proust, and Kafka, it takes on transformative powers and continues to grow long after its human "creator" has physically died.

The authority and status we attach to the term "author" are special and definitive in nature. Foucault writes:

A private letter may well have a signer - it does not have an author; a contract may well have a guarantor - it does not have an author. An anonymous text posted on a wall probably has an editor - but not an author. The author function is therefore characteristic of the mode of existence, circulation, and functioning of certain discourses within a society" [13] (p. 211).

His use of the work "function" is key to his perception of identity in this essay. By being designated as a function, the author becomes part of a process that produces meaning via the text. Writing suddenly moves from a foundational to a functional principle and the author is merely part of the productive process. Initially, Foucault points out, there was a time in which great texts (narratives, stories, epics, tragedies, comedies) were routinely accepted without any question about authorship. What the work said to the masses was considered paramount to who wrote it.

In the Middle Ages, a distinct shift occurred among scientific texts. They were not considered "true" or "valid" unless marked by the name of their author [13]. This is the point, Foucault believes, in which the idea of author began to play a paramount role in how a work is perceived. The concept of authorial intent began to emerge and take precedence, rather than the concept of a text and the reader creating a shared realm via a transactional relationship.

Some of Foucault's most telling evidence of a discoursemediated identity is included in his discussion of the various "selves" involved in the authorial function as well as the subsequent discourses a text can give rise to even after the author has died. Concerning the "selves," Foucault writes that at different times an author will possess distinctly different identities, such as the voice used in a narrative account versus the voice used in the preface of a text. When the author analyzes his or her work after it is published, yet another "self" is required. None of these "selves" is wholly descriptive, yet all are present as one time or another.

There is a definite point when a break occurs between the author and the text, usually once the work is offered for public consumption. At this point the text becomes an independent entity and begins to give rise to numerous subsequent and independent discourses. These discourses can go on forever, depending on how well the text is accepted. This is the point where a term such as authorial intent becomes blurry for Foucault. Even though the author (while living) may of- fer a rationale behind various parts of the text, it is the reader who ultimately creates meaning in his or her mind. Once the author is dead, this process of reader-generated meaning becomes even more pronounced.

In The Discourse on Language, Foucault expands somewhat on author and identity, particularly the successive discourses and disciplines that arise when the public reads a text [8]. He writes:

But the principles involved in the formation of disciplines are equally opposed to that of commentary. In a discipline, unlike in commentary, what is supposed at the point of departure is not some meaning which must be rediscovered, nor an identity to be reiterated; it is that which is required for the construction of new statements. For discipline to exist, there must be the possibility of formulating — and in doing so ad infinitum — fresh propositions (pp. 222-23).

Within this passage, Foucault illustrates the independent nature (identity, if you will) a text achieves once it is read and interpreted by the reader. The author has served his "function" and assisted in producing meaning, but once that meaning is made available to the public, a new form of production is generated, that being the production of new discourses.

Perhaps Foucault's most vivid comment on identity came late in his life during a 1982 interview in Toronto when he rather wryly proclaimed: "To be the same is really boring" [11] (p. 166). His comment concerned the various relationships we have with ourselves. They are not, he said, relationships of identity but rather relationships of "differentiation, of creation, of innovation" [11] (p. 166). This again illustrates the chameleon-like tendencies that Foucault sees for our identities. It also exemplifies how his views on identity became more concentrated late in his life. Just 13 years earlier, in "What is an Author?" Foucault's perceptions of identity were somewhat broader, using the author as a focal point. In his 1982 lecture, just two years before his death, his focal point is clearly the individual.

\section{Foucault's Identity and the Ethico-political: Discipline and Punish}

The unforgettable first chapter of Discipline and Punish begins with the macabre torture and dismemberment of the accused, Damiens. It is the mid-eighteenth century, a period when public torture and execution are commonplace. The practices are a powerful way for the monarchy to illustrate its dominance. Horribly inhumane acts are committed against Damiens: His flesh is torn from his body, the knife with which he allegedly committed the crime is fused to his right hand with burning sulphur, each of his limbs is shackled to a horse and his body pulled apart. The body parts are then burned [6].

Throughout the majority of this torture, Damiens lives and prays to God for a pardon. Even after his body is torn apart, his mouth is seen moving, as if attempting to speak. In the most vivid manner, Damiens is reduced from a living person to nothing but a smoldering heap of remains. His identity is literally stripped away.

Foucault names Damiens in Discipline and Punish, and he is a focal point at which the reader can identify with the 
hideous power of the monarchy. Yet Damiens accomplishes a secondary function: Although he has a name and works as a character with a fixed identity, he is also illustrative of what happens to anyone who commits a crime against the monarchy.

Identity moves throughout this text in a Foucauldian discursive manner. It is bolstered and defined by the varying narratives of Discipline and Punish. Damiens is named, as is the executioner Samson, who systematically engages new and different forms of torture, all designed to punish Damiens, of course, but they are also intended to send a message to all of the monarchy's subjects. Identity, in the form of Damiens, becomes a symbol from which everyone is expected to learn. It was punishment through spectacle.

A distinct ethical component begins to emerge in Discipline and Punish and this component is directly linked to Foucault's idea of the unfixed identity. Years after Damiens' execution, Foucault describes a period in which the evil of the monarchy is turned back upon itself and the accusers suddenly become the accused. In this case - the individual in question again is named - Montagne is accused of being the leader of a gang guilty of smuggling. The Compagnie des Fermes published fliers depicting him as “... a wild beast, a second hyena to be hunted down" [6] (p. 66). Foucault writes:

But the effect, like the use, of this literature was equivocal. The condemned man found himself transformed into a hero by the sheer extent of his widely advertised crimes, and sometimes the affirmation of his belated repentance. Against the law, against the rich, the powerful, the magistrates, the constabulary or the watch, against taxes and their collectors, he appeared to have waged a struggle with which one all to easily identified [6] (p. 67).

Montagne, and many criminals before and after him, were perceived as Robin Hood-like folk heroes who deserved to be protected and revered. They were striking out at the numerous ills of society that collectively repressed most of the citizenry. The executioners were seen as evil representatives who dumbly followed the orders of an unscrupulous monarchy, never questioning them. When an accused was made an example, it often times had the opposite effect.

Foucault is able to weave this ethical component into Discipline and Punish, and it is directly linked to identity. In the above example, Montagne, like all the other criminals, possessed what is commonly accepted as an identity: a name, a function in society (even if that function is deemed criminal), and a certain embedded agency. However, these criminals also were examples of Foucault's unfixed identity. The backlash that resulted from their torture and execution is a clear example. Montagne becomes representative of what can happen to anyone and everyone at any moment under the unrepresentative rule of a monarchy. His folk hero status is a unifying force for all oppressed people of the monarchy. The subjects may still identify Montagne by name but his unfixed identity - that which is determined by the inhuman torture to which he is subjected - becomes the instrument for action.

The monarchy skillfully embedded a sense of "good" within subjects who were obedient and a sense of "bad" within those who were lawless and disobedient. The monarchy established the laws that mediated this good/bad dichotomy. Unbeknownst to the monarchy, however, the very methods by which it sustained its tight grip on the people (i.e., the fear of being tortured or executed) became the forces that eventually undermined the monarchy's control.

The divine right of kings was the monarchy's way of justifying its control as well as its utter disregard for human rights. Because the divine right of kings assumes the approval of God, the monarchy could claim a certain vulgar ethical basis no matter how inhumane its actions may have seemed. The monarchy was practicing pure emotivism because it defined the just and the ethical in a manner that was beneficial to the preservation and longevity of the crown. An incident such as Montagne's is significant because it illustrates a collectivist ethic that is motivated in part by the punishment doled out to one man but more so by the realization that without action any person could in essence be a Montagne. His status transforms from a fixed identity to an unfixed identity that is mediated and determined by the circumstances surrounding it.

Foucault explains this process of mediation and determination in The Archaeology of Knowledge. He writes:

The positions of the subject are also defined by the situation that it is possible for him to occupy in relation to the various domains or groups of objects: according to a certain grid of explicit of implicit interrogations, he is the questioning subject and, according to a certain programme of information, he is the listening subject; according to a table of characteristic features, he is the seeing subject, and according to a descriptive type, the observing subject; he is situated at the optimal perceptual distance whose boundaries delimit the wheat of relevant information [8] (p. 52).

The subject in this passage experiences a variant of situations, each markedly altering the subject's status. Montagne - or any of the other prisoners in Discipline and Punish undergoes a similar transformation that is mediated by the different situations they face. More relevant is the effect that transformation has on the people surrounding the subject.

\section{A Cultural Identity and the Ethical: The History of Sexuality}

For a complete understanding and appreciation of the part an unfixed identity plays in moving humans beyond emotivism and egoism and toward a more narrative-based ethic, it is necessary to examine how Foucault's perceptions of identity can be determinative on a cultural basis.

In The History of Sexuality, Foucault begins with a very old Victorian "story" and attempts to uncover the discourse that has sustained the story for centuries. The fairly frank and open sexual practices of the seventeenth century were steadily replaced by the stringent rules of the Victorian bourgeoisie. Sexuality became more confined and moved behind closed doors. "On the subject of sex," Foucault [7] writes, "silence became the rule" (p. 3).

The identity of the culture began to change also. Sex became a topic to be studied and regulated by way of science and the courts. Prostitution was outlawed and sex became a topic to be evaluated by psychiatrists. This repression had a 
backlash, however. Rather than acting as a prevention of sexuality, repression became an incitement. To isolate and expose the dynamic behind this backlash is to uncover how Western culture has been defined by sexuality. "The object," Foucault [7] writes, "in short, is to define the regime of power-knowledge-pleasure that sustains the discourse on human sexuality in our part of the world" (p. 11).

Foucault uses the genealogy to illustrate how sexuality was placed into Victorian discourse for a reason: To ultimately repress it. This process involved the church constituting sex as something that had to be confessed [7]. "The Christian pastoral," he writes, "prescribed as a fundamental duty of the task of passing everything having to do with sex through the endless mill of speech" (p. 21). This verbalization of sexual infractions included certain labels (like scandalous and sinful) that were determined by the monastery. In the eighteenth century sex moved into the realm of the courts and became a "police matter" (p. 24).

The movement of sexual conduct into the courts is notable because it marks a change in perception. No longer was sex viewed as a personal activity; it was now a population issue. Once again, Foucault uses the story of an individual to illustrate his point. His story involves Jouy, a simple-minded farm hand from the village of Lapcourt, France, in 1869. Police questioned Jouy because the parents of a local girl had accused him of touching her inappropriately. The significance of this story is that Jouy was not arrested. Instead he was placed in a hospital and studied for the rest of his life. Sex was now a matter of science to by analyzed in the laboratory. It also became a topic that was discussed less frequently in public. Sex became something to be whispered about.

Again in The History of Sexuality Foucault is able to focus on the topic of sex and personalize it through individuals with seemingly fixed identities. As sex becomes a broader discourse (and especially judicial and scientific discourses), its identity also changes. It becomes more complex issue, one involving cultural distinctions and attributes, rather than personal preferences.

Foucault broadens this cultural identity through the notions of scientia sexualis and ars erotica [7]. Scientia sexualis is the traditional Western view of sex that is mediated by confession, which, Foucault writes, "... became one of the West's most highly valued techniques for producing truth" (p. 59). Concerning this cultural link, Foucault writes:

The transformation of sex into discourse, which I spoke of earlier, the dissemination and reinforcement of heterogeneous sexualities, are perhaps two elements of the same deployment: they are linked together with the help of the central element of a confession that compels individuals to articulate their sexual peculiarity - no matter how extreme. In Greece, truth and sex were linked, in the form of pedagogy, by the transmission of a precious knowledge from one body to another; sex served as a medium for initiation into learning. For us, it is in the confession that truth and sex are joined, through the obligatory and exhaustive expression of an individual secret. But this time it is truth that serves as a medium for sex and its manifestations [7] (p. 61).
Within this section, Foucault expands the cultural view of sexual identity by contrasting the West's views of sex to those of Greece. Identity again is not a fixed entity but something that is governed by the culture in question.

The concept of ars erotica in turn broadens the topic even more. Foucault writes that in societies like China, Japan, India, Rome, and the Arabo-Moslem societies [7]:

... truth is drawn from pleasure itself, understood as a practice and accumulated as experience; pleasure is not considered in relation to an absolute law of the permitted and the forbidden, nor by reference to a criterion of utility, but first and foremost in relation to itself; it is experienced as pleasure, evaluated in terms of its intensity, its specific quality, its duration, its reverberations in the body and the soul (p. 57).

Like Discipline and Punish, there is a subtle communitarian ethical note in The History of Sexuality. Foucault advocates a cultural form of action in which we must recognize and reverse the direction of the numerous analyses. He concludes:

Rather than assuming a generally acknowledged repression, and an ignorance measured against what we are suppose to know, we must ... investigate the conditions of their emergence and operation, and try to discover how the related facts of interdiction or concealment are distributed with respect to them [7] (p. 73).

This collective recognition provides the possibility for change, but it involves first a realization of identity and then a movement beyond identity. A major part of Foucault's genealogy is the narratives and social practices that make up our culture. Unlike Nietzsche, Foucault seems to be allowing a space for these narratives and social practices to continue. To completely dismantle them would involve doing away with the very cultures he is using in his genealogy. Instead Foucault appears to be advocating a narrative-based form of ethics, though he never uses those words.

\section{A Movement Beyond Identity: Technology of the Self}

Of the four "technologies" Foucault addresses in "Technologies of the Self," [11] the first two, the technology of production and the technology of sign systems, deal primarily with the study of the sciences and linguistics. It is the final two, the technology of power and the technology of the self, which are most applicable to this essay. The technology of power and how it transforms otherwise free-thinking beings into mere subjects has been a subtheme in the earlier discussions of Discipline and Punish and The History of Sexuality. The final technology, the technology of the self, is most useful to helping us move beyond emotivism and egoism toward a narrative-based ethic. Specifically, the technology of the self can be defined in part as "... the ways in which we relate ourselves to ourselves, contribute to the forms in which our subjectivity is constituted and experienced ..." [14] (p. 119).

Foucault immediately anchors the technology of the self in a Greco-Roman philosophy that advocates the "care of the self." This viewpoint has faded somewhat over the years, and Foucault writes in "Technologies of the Self": 
When one is asked 'What is the most important moral principle in ancient philosophy?' the immediate answer is not 'Take care of oneself' but the Delphic principle, gnothi seauton ('Know yourself') [11] (p. 226).

Our philosophical tradition has overemphasized the latter and forgotten the former, Foucault writes. The statement "Know yourself" in the Delphic principle was not an abstract form. Rather, it was technical advice: "Do not suppose yourself to be a god" [11] (p. 226). In a sense it is classic and very sound advice for avoiding egoism. By not supposing oneself to be a god, a person naturally assumes a greater sense of responsibility toward the other, and this underscores the significance of the technology of the self. The gods, after all, need only to be true to themselves. The human condition is a fragile construction made up of a myriad of individual contributions.

The technology of the self involves a rigorous selfexamination and confession aimed at ultimately moving beyond the self, best expressed by Foucault's concept of "the death of man" [15] (p. 130). By recalling Foucault's theme of the prison, his death of man proclamation is an emancipation from the prisons of thought and action that shape our politics, our ethics, and our relations to ourselves $[16,17]$.

Outwardly this concentration on the self may appear as pure egoism. However, Foucault consistently reminds us that intersubjectivity is the key to a working ethics for all. His radical intersubjectivity is based on someONE happening with others [18]. The emphasis always has to be on interaction with others. By finding this solace among others, Foucault provides for a way to "... get free of oneself" [16] (p. 152).

These realizations came late in Foucault's life and enabled him to merge many of the themes he had earlier written about in singular fashion [19]. Foucault sees ethics as an entity that is pushed and pulled by the binary oppositions of constraint and freedom: Too much of oneself constrains ethics and the freedom of a multitude of voices propels an ethic of action. On the other hand, an unbridled collection of voices can be just as restrictive. The answer resides in a balance between the two undergirded by critical thinking. Even in the worst of times, Foucault believes in an ethic of transgression where good can be salvaged from the ruins [20]. To achieve this ethical salvation, one must first know oneself well enough to break free of the bonds of self and discover an agency that can bring about change. By accentuating this ethical care of the self, Foucault enables the subject to assume responsibility without violating the integrity of the other [21].

Late in his life, Foucault hinted at the idea of moving beyond identity (or the self) when he defined ethics as the "process in which the individual delimits that part of himself that will form the object of his moral practice, defines his position relative to the precept he will follow, and decides on a certain mode of being that will serve as his moral goal" [22] (p. 26-28). What this passage appears to advocate is a rediscovery of the self with the express intent of utilizing only the best precepts to serve the moral goal in question.

\section{DISCUSSION AND CONCLUSION}

\section{Beyond Identity and Toward a Narrative-based Ethic}

This project established as its objective not only to define Foucault's view an unfixed, discourse-mediated identity but also to show that unfixed identity in action within two of his major works, Discipline and Punish and The History of Sexuality. The various characters in these two texts whether individual prisoners in Discipline and Punish or the Western culture in The History of Sexuality — did exhibit the characteristics of a discourse-mediated identity. At times they were individuals with names and positions within society but at other times their identities were changed by the various circumstances surrounding them. These identity permutations often had wide-scale effects that otherwise may not have occurred. The torture of one prisoner suddenly reminded everyone of the tyrannical power of the monarchy and the result was a backlash against that power. It was not the fixed identity of one prisoner but the broader identity mediated by the torturous punishment doled out to this prisoner that was the impetus for collective action and change.

The broader cultural identity exhibited in The History of Sexuality also changed depending on the different periods of history. The influence of the courts changed the identity somewhat, but the influence of science altered it even more. Each discourse pulled and shaped the sexual identity of the Western culture and this identity will continue to be modified.

There is an ethical component embedded in this everchanging identity and Foucault addresses it through his technology of the self. Because his technologies were addressed late in his life, each is a valuable lens through which to view ethics. Especially significant to this project is the technology of the self because it suggests a specific manner of moving beyond the self (where emotivism and egoism reside), or, as Foucault says, to "get free of oneself" [22] (p. 8-9). Once this is accomplished, identity - whether fixed or discoursemediated - becomes in a sense a process of unfolding, a relational interaction between the good and bad of life, always in the process of becoming.

This Foucauldian notion of getting free is complex, especially when one looks at his work in totality. His early works suggest definite subjectivity and leaves little room for modification. Later in his life, the very idea of ethics was dependent on consideration of the other and a moving beyond the self $[17,18]$. This movement, like the aforementioned process of identity unfolding, is where change can begin. Each of us has within himself or herself the capability to overcome emotivism and egoism and become an active cog in a collective narrative-based form of ethics.

\section{ACKNOWLEDGEMENTS}

None declared.

\section{CONFLICT OF INTEREST}

None declared.

\section{REFERENCES}

[1] Nietzsche F, Kaufmann W, Eds. On the genealogy of morals. New York: Vintage Books; 1989.

[2] Deleuze G. Nietzsche \& philosophy. Tomlinson H, Trans. New York: Columbia University Press; 1983. 
[3] Derrida J. Structure, sign, and play in the discourse of the human sciences. In: Con Davis R, Schleifer R, Eds. Contemporary literary criticism (2nd ed.). New York: Longman Inc. 1989; 230-47.

[4] Derrida J. The principle of reason: The university in the eyes of its pupils. In: Con Davis R, Schleifer R, Eds. Contemporary literary criticism (2nd ed.). New York: Longman Inc. 1998; 345-62.

[5] Spivak G. Feminism and critical theory. In: Latimer D, Ed. Contemporary critical theory. San Diego: Harcourt Brace Jovanovich. 1989; 634-58.

[6] Foucault M. Discipline and punish: The birth of the prison. New York: Vintage Books; 1995.

[7] Foucault M. The history of sexuality Vol. 1: An introduction. Hurley R, Trans. New York: Vintage Books; 1978.

[8] Foucault M. The Archaeology of Knowledge, New York: Pantheon Books; 1972.

[9] Fisher W. Human communication as narration: Toward a philosophy of reason, value, and action. Columbia: University of South Carolina Press; 1989.

[10] Fisher W. Clarifying the narrative paradigm. Comm Mono 1989; 56: 55-8.

[11] Foucault M. Technologies of the self. In: Rabinow P, Ed. Michel Foucault: Ethics, subjectivity and truth. New York: The New Press; 1994; 223-51.

[12] Sawicki J. Foucault, feminism and questions of identity. In: Gutting G, Ed. The Cambridge companion to Foucault. Cambridge University Press; 1994.
[13] Foucault M. What is an author? In: Rabinow P, Ed. Aesthetics, method, and epistemology. New York: The New Press; 1998.

[14] Davidson A. Ethics as ascetics: Foucault, the history of ethics, and ancient thought. In: Gutting G, Ed. The Cambridge Companion to Foucault. Cambridge: Cambridge University Press; 1994; 115-35.

[15] Deleuze G. Foucault. Hand S, Trans. Minneapolis: University of Minnesota Press; 1986.

[16] Bernauer J, Mahon M. The ethics of Michael Foucault. In: Gutting, G, Ed. The Cambridge companion to Foucault. Cambridge: Cambridge University Press; 1994; 141-156.

[17] Nuyen AT. The politics of emancipation: From self to society. Hum Stds 1998; 21: 27-43.

[18] Biesta G. Radical intersubjectivity: Reflections on the "different" foundations of education. Stds in Phil and Ed 1999; 18: 203-20.

[19] Ewald F. Foucault and the contemporary scene. Phil and Socl Crit 1999; 25: 81-91.

[20] Landry L. Beyond the french fries and the frankfurter. Phil and Socl Crit 1999; 26: 99-129.

[21] Gordon N. Foucault's subject: An ontological reading. Polity 1999; 31: 395-414.

[22] Foucault M. The history of sexuality Vol. 2: The use of pleasure. Hurley R, Trans. New York: Vintage Books; 1986. 